\title{
Business Impact and Policy on the Major Players in the Market of the Development of Distributed Energy in China
}

\author{
Y. X. He, Y. Xu, T. Xia, and J. X. Zhang \\ School of Economics and Management, North China Electric Power University, Zhu Xin Zhuang, Bei Nong Road No. 2, \\ Changping District, Beijing 102206, China
}

Correspondence should be addressed to Y. X. He; yongxiuhe@126.com

Received 4 November 2015; Revised 21 February 2016; Accepted 16 March 2016

Academic Editor: Ruben Specogna

Copyright (C) 2016 Y. X. He et al. This is an open access article distributed under the Creative Commons Attribution License, which permits unrestricted use, distribution, and reproduction in any medium, provided the original work is properly cited.

\begin{abstract}
As an effective measure for the promotion of the adjustment of China's energy structure, distributed energy and its reasonable planning and development will have a significant impact on the major players in China's power market. With the increasing access to distributed energy, its beneficial impact on the major players in the power market will become increasingly obvious. This paper examines the influence of access to distributed energy on the development of the major players in the power market, especially power supply enterprises. On this basis, a model for the calculation of the profits and losses of distributed energy users and power supply enterprises has been established, and the specific impact on the profits of power supply enterprises after access to distributed energy becomes available can be measured. In addition, this paper puts forward related policy suggestions to be implemented after access to distributed energy becomes available based on the results of the aforementioned measurement, in order to guarantee a reasonable profit for the major players in the power market during the process of the development of distributed energy and to promote the healthy and orderly development of distributed energy.
\end{abstract}

\section{Introduction}

With the deepening impact of global climate change on human survival, the development of clean energy is widely appreciated [1]. Distributed power is an important means to improve the efficiency of the utilisation of clean energy and to provide cities with clean electricity; its development and application have been considered by many countries [2]. However, access to distributed energy will have a range of effects on the business development and economic benefits of the major players in the power market. At present, the development of distributed energy lacks a standardised policy system, the relevant subsidy policy, prices, and taxes are different with local government, and other market-based incentive mechanisms have not been fully implemented. Therefore, it is necessary to establish a complete evaluation system to evaluate the practical feasibility of distributed energy in every country. Tshewang aimed at a methodology for evaluation of DG as an alternative path to rural electrification in Bhutan. An algorithm based on a set of criteria is proposed to evaluate different DG options. The leveled energy cost can then be used to select the cheapest option from the most feasible options obtained from the evaluation [3]. This is also necessary to promote adjustments in China's energy structure and reforms in the power market in order to maintain balance in the interests of all parties. In turn, this will make China's energy development more diversified and its energy consumption more reasonable, and it will provide effective support for the promotion of its energy revolution and its climate change adaptation strategies.

Many research studies on distributed energy have been conducted; however, in the process of its popularisation and application, distributed energy has also faced many problems involving cost, economy, environment, energy security, and power quality [4]. Information Gap Decision Theory is also used to solve the problem of congestion and voltage management caused by diverse renewable energy sources. For an acceptable amount of tolerance, the coordinated reactive power dispatch of distributed generation (DG) and active power schedule of optimally sited demand response (DR) nodes can be used to ease congestion and manage power flow on a section of distribution network, accommodating the 
uncertain nature of wind power generation [5]. Calculating the optimizing quantity became more complicated which was mainly because distribution network operators (DNOs) are faced with the uncertainties related to the decisions of DG investors/operators where some of them can be probabilistically modelled while the others are qualitatively treated. Comparing the possibilistic-scenario model with fuzzy-Monte Carlo approach shows that it can give an accurate result with much less computational burden [6]. From the perspective of China's distributed energy policy, electricity market reform in China is underway, and China faces great many challenges as it tries to transform both its economy and its institutions at the same time. For this to happen, China might develop a multidimensional approach in the energy sector that goes beyond the current practices of developed economies because even these have not been successful in curbing environmental destruction [7]. With the rapid development of distributed energy, small power generation equipment has begun to obtain access to the transmission network; the effective interconnection of distributed energy relies on a reform of the grid and improvements in the infrastructure to enable it to cope with an increasingly complex network system [8]. Meanwhile, the problem of the extension of the transmission network becomes increasingly important after access to distributed energy is obtained, and a dynamic model aimed at costs and emissions can be applied to solve this problem [9]. Many rural countries provide other alternative options to grid extension, for example, off-grid decentralized renewable energy (DRE), which exist, are often more attractive financially, and could be promoted more effectively [10]. These technologies can be cheaper than grid extension, even on a like-for-like comparison. DRE technologies also provide opportunities for development, even without driving large productive loads. So far, the promotion of DRE in Laos has not always been successful, but this should not be an argument against promoting these options. A close look at recent rural electrification project budgets reveals indeed that grid extension is far more subsidised than DRE, raising concerns about the social equity of such projects [11]. When solar distributed energy is connected to the grid, it is shown that the insertion of this kind of energy on a large scale can cause important changes in the direction of the power flow of the electric distribution grid, reducing the effectiveness of the existent protection devices and increasing voltage imbalances [12]; as a result, reasonable supporting policies are needed for its orderly development [13]. At present, the study of distributed energy in China is relatively fragmented, and a complete research system is lacking; additionally, its corresponding policy system is also imperfect. These factors are not conducive to the long-term development of distributed energy.

In terms of the impact of the development of distributed energy on the major players in the market, there are likely to be a variety of effects because of the numerous benefits of access to distributed energy. The limitations on the development of distributed energy in China are mainly concentrated around the conflicts of interest between core market subjects; the government needs to adjust the present market mechanisms and development models to ensure the reasonable and orderly development of distributed energy [14]. Through an analysis of the development of China's policy regarding distributed photovoltaic (PV) and simulations of different market situations in the development of distributed $\mathrm{PV}$, we can help to address the problem of the relevant costs and market constraints during the process of the development of distributed PV [15]. Meanwhile, a dynamic price mechanism will be important to respond to the demand for and access to distributed energy [16]. Additionally, subsidies for distributed energy can help the users reduce the cost in electricity expenditures and environmental management. When subtracted from the total subsidy a net cost of RES$\mathrm{E}$ of $2.3 \mathrm{~B} €$ is derived. Wind, biomass, and small hydroelectric power had negative net costs (i.e., net benefits) while photovoltaic and solar thermal power had negative net costs [17]. Moreover, through a solar home system (SHS) case project in Alumar Island, Philippines, the performance of users to sustain their systems was assessed using a novel approach proposed, and it was found that project beneficiary selection process could be improved with the capability of predicting the performance of user [18]. In terms of the investment in the renewable energy market, many key factors should be considered [19]. Moreover, the major players in the market should be regulated by reasonable policies after largescale access to distributed energy becomes available [20]. In general, large-scale access to distributed generation (DG) will affect the structure of China's electric power market and will have an impact on the benefits to each market subject. At present, China lacks an analysis of the operating conditions of the major players in the market after access to distributed energy becomes available. This means that the interests of the major players in the market cannot be guaranteed; thus, it is necessary to analyse the impact of access to distributed energy on the operating conditions of the major players in the market in order to understand the profit conditions of each body and put forward reasonable policies and suggestions.

The major body of this paper consists of the following parts: Section 2 introduces the present situation and the policies related to the development of distributed energy in China and puts forward a business impact analysis model for the major players in the power market based on the distributed energy development policy; further, it analyses the influences of the distributed energy development policy from two angles, that is, the benefits of a distributed enterprise and the benefits of a power supply enterprise. Section 3 utilises the power supply enterprise in S province's grid as an example; it calculates the total impact on the profits of the power supply enterprise in $S$ province's grid of the development of distributed energy in such grid. Section 4 combines the results with the situation of the development of distributed energy in China to do some discussion. Section 5 provides conclusions and puts forward corresponding policy recommendations based on the results of the analysis.

\section{Methods}

To analyse the business impact and policy research on the major players in the market of the development of distributed energy in China, this paper concludes the background of the 
development of distributed energy in China and conducts the management impact analysis of the major players in the market. Through the analysis regarding the distributed enterprise and the grid power supply enterprises with different angles and models, the benefits and losses of the major players in the market can be calculated and the related problems can be found.

2.1. Background. China clearly supports an acceleration in the development and utilisation of wind power, solar power, small hydro, biomass, ocean energy, and geothermal and other renewable energy sources in its twelfth five-year plan for energy development. In recent years, solar, wind, and other renewable and distributed energies have begun to obtain large-scale access to the grid, and the development of distributed energy has been healthy. China has formulated a series of policies which encourage the development of distributed power in order to ensure its healthy and orderly development and provide security for the generation of distributed energy. The specific policies are shown in Table 1.

Overall, policy guidance in China supports and encourages the development of distributed energy. Table 1 shows that China has put forward a series of supporting policies to encourage the development of distributed energy. They cover management, access and operation, feed-in tariffs and subsidies, and taxes regarding distributed power in an effort to provide solutions to the problems affecting the process of the development of distributed energy. However, the research related to distributed energy is still lacking; China still faces many problems in the process of the developing distributed energy, as the policies regarding the costs of power generation, electricity price mechanisms, access costs, reserve costs, parallel mechanisms, and incentive mechanisms are not perfect. These imperfect policies have an impact on the management of the major players in the market and cause an imbalance in the distribution of the relevant interests, which, in turn, hinders the further development of distributed energy. Accordingly, it is necessary to conduct a business impact analysis on the major players in the power market to improve the relevant policies and promote the healthy and orderly development of distributed energy.

\subsection{Management Impact Analysis of the Distributed Enter-} prise. In order to encourage the development of distributed energy and bolster its promotion by distributed enterprises, China has established a series of feed-in tariff and subsidy policies related to distributed energy to ensure that the benefits of distributed enterprises are reaped. In general, at present, China has implemented many preferential policies for distributed enterprises to ensure their accessibility; their specific content mainly deals with power generation, taxation, access costs, and reserve costs. These measures have had a significant impact on the management of distributed enterprises.

In terms of the costs of distributed enterprises, three aspects have been affected by these policies: access costs, reserve costs, and taxes. Regarding access costs, grid enterprises invest in the access systems of large- and medium-sized renewable energy power generation projects that have direct access to the grid. The access system investments of small renewable energy power generation projects are negotiated between the power generation enterprises (individually) and power grid enterprises. In general, most of the access costs are absorbed by the power grid enterprises. Regarding the reserve costs, distributed PV power and wind power projects are not charged system reserve capacity fees, although other types of distributed power projects are charged according to state regulations. In general, the current policies regarding the reserve costs of distributed energy are imperfect and have not been standardised. Regarding taxes, the government offers many preferential tax policies for distributed enterprises, including value-added tax relief and enterprise income tax relief. With respect to taxes, the first three years of an enterprise are exempted from income taxes, and the income taxes for next three years are cut in half; this tax relief starts in the year when the enterprise receives its first production and operation income. In terms of the benefits of distributed enterprises, the role of subsidies is obvious. The government provides a corresponding subsidy for its power generation, and the fee is paid by the renewable energy development fund and is transferred by the power grid enterprises.

In summary, the government has provided many preferential policies to guarantee profits for distributed enterprises and to encourage their development in order to realize the rapid development of distributed energy.

\subsection{Management Impact Analysis Regarding Grid Power Supply Enterprises}

2.3.1. A Power Market Overview and Reform Prospects in China. The electricity market model can generally be divided into four categories, namely, the vertical integration mode, the single buyer mode, the wholesale competition mode, and the retail competition mode. However, the impact of distributed energy on the major players in the market is different in these four modes. At present, China is in the wholesale competition mode. In this kind of competition mode, the distribution side has not been separated, and large users have certain options on the sales side. Consequently, large users can sign a direct power supply agreement with the generators to conduct power trade, while small- and medium-sized users lack a corresponding option and can only deal in accordance with the established price. With large-scale access to distributed energy, the role of small- and medium-sized users begins to change: DG users will be not only the consumers of power, but also the suppliers of electricity. This extends the purchasing options of small- and medium-sized users, so that they can purchase electricity from the rest of the DG users, rather than grid power supply enterprises. In general, access to distributed energy will enable power users to have greater autonomy and will promote reform and development in China's power market.

With the continuous development of the power market in China, reforms in the power market are constantly advancing. The goal of reforms in China's power market is to build an effective market structure and system, so as to encourage the formation of a market-based pricing model. During the process of power market reforms, the role of grid power 
TABLE 1: The development policy system for distributed energy in China.

\begin{tabular}{|c|c|c|}
\hline Time & Government agency & Policy document \\
\hline 2009 & National Treasury & Opinions on accelerating the implementation of solar PV building applications \\
\hline 2011 & NDRC & Notice on improving the policy of solar PV tariff \\
\hline 2012 & National Treasury & The funds management of additional subsidy on renewable energy electricity price \\
\hline 2013 & NDRC & Interim measures for the management of distributed power generation \\
\hline 2013 & NDRC & $\begin{array}{l}\text { Notice on the additional standards about the adjustment of renewable energy electricity price } \\
\text { and the matters related to environmental protection electricity price }\end{array}$ \\
\hline 2013 & NDRC & $\begin{array}{l}\text { Notices on playing the price leverage to promote the healthy development of the photovoltaic } \\
\text { industry }\end{array}$ \\
\hline 2013 & NEA & Opinions on developing the distributed generation \\
\hline 2013 & NEA & Interim measures on the project of photovoltaic power plant \\
\hline 2013 & National Treasury & Notice on the policy of photovoltaic VAT \\
\hline 2013 & SGCC & Opinions on the distributed power grid service \\
\hline 2013 & SGCC & Opinions on the management of promoting the access of the distributed power \\
\hline 2013 & SGCC & Technical specifications on the access of distributed energy \\
\hline 2014 & NEA & Notice on the further implementation of distributed PV policy \\
\hline
\end{tabular}

companies in the power market will dramatically change: grid power supply enterprises will only charge a fixed transmission and distribution tariff after a corresponding calculation rather than difference between purchase and sales price. Thus, users of distributed power will gain greater autonomy. In general, with the advancement of power market reforms, the management mode of grid power supply enterprises will undergo huge changes. Moreover, the impact of the development of distributed energy policy on grid power supply enterprises will be different. Accordingly, the method used to calculate the impact and the degree of impact of distributed energy development policy on the business of grid power supply enterprises will also change, along with future changes in the position of the power grid. The effects of access to excess distributed electricity and some current electricity price policies on power grid companies may shift with the changes in their profit patterns. However, at present, power grids still run on the basis of the difference between the purchase and sale prices in their actual operation process; and this pricing mechanism may continue for a long time for most of their users. Accordingly, this research will adopt the difference between the purchase and sale prices to analyse the profit of power grid enterprises. Of course, with the advancement of the reforms, the difference between the purchase and sale prices will be replaced by the fixed transmission and distribution tariff. In addition, the effects of access to excess distributed electricity and the mode of determining electricity prices will change, and the effect of distributed energy on the management of grid power supply enterprises will also be different. Overall, currently, the effect of access to distributed energy on grid power supply enterprises is still based on the main mode of management of the current power grid. With the advancement of reform, the relevant models will need to be adjusted dynamically.

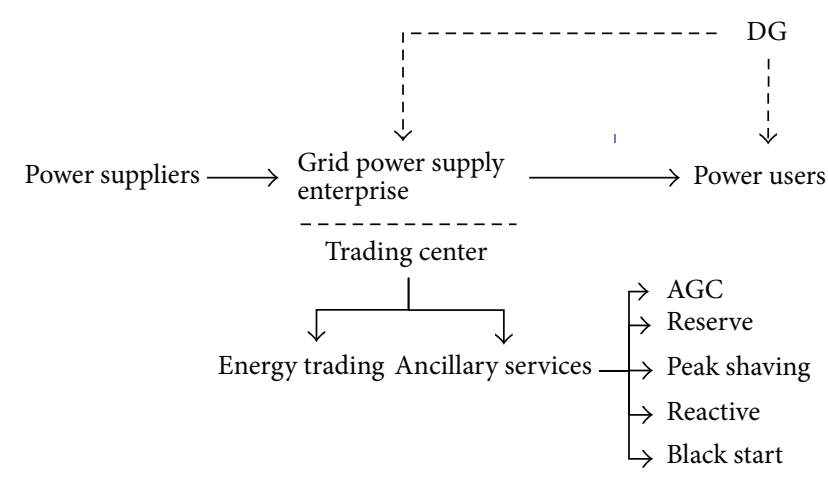

Figure 1: The structure of the power market after access to distributed energy becomes available.

of the DG industry, the construction of a smart grid is constantly achieving breakthroughs. The large-scale access to DG has affected the structure of the power market in China and has made a huge impact on the economic interests of the major players in the market. Meanwhile, the costs and benefits for grid power supply enterprises will also change with large-scale access to distributed energy. The structure of the power market after access to distributed energy becomes available is shown in Figure 1.

Figure 1 shows that power can only be unidirectionally transmitted from power suppliers to power users through the transmission and distribution network in the traditional power market. However, with access to distributed energy, the power flow in distribution network should be bidirectional. The power users equipped with the distributed energy are not only merely the buyers of power, but also power producers with redundant DG power. The access to DG enables the distribution network to be an interconnected network, instead of the original center radiation network. This breaks the traditional centralized power supply mode and changes the costs and benefits for grid power supply enterprises. The 
TABLE 2: The cost and benefits of grid power supply enterprises after access to distributed energy becomes available.

\begin{tabular}{ll}
\hline Profit & Cost \\
$\begin{array}{ll}\text { (1) The expenses that the users buy the } \\
\text { electricity from grid power supply enterprise }\end{array}$ & $\begin{array}{l}\text { (1) The private use of distributed energy produces the opportunity cost of the } \\
\text { reduction of sales electricity in grid power supply enterprise }\end{array}$ \\
$\begin{array}{ll}\text { (2) The expense of alternate service (China } \\
\text { has not conducted it) }\end{array}$ & (2) The purchase cost of access to excess distributed electricity \\
$\begin{array}{l}\text { (3) Reducing or delaying investment in } \\
\text { upgrading transmission and distribution }\end{array}$ & (3) Ancillary service costs of the distributed power (the grid does not need to bear \\
lines (requiring specific conditions and & currently) \\
sometimes there is no such income) & (4) The increase of the access cost, related upgrading investment, operation and \\
(4) Reducing line losses (sometimes there is & maintenance costs, and marketing service. \\
no such income)
\end{tabular}

specific impact on the costs and benefits for grid power supply enterprises is shown in Table 2.

In general, there are a variety of business impacts on grid power supply enterprises after access to DG becomes available. It is important to consider the impact of these factors on the benefits and costs of grid power supply enterprises comprehensively, so as to provide a reasonable measurement of the business conditions of grid power supply enterprises after access to distributed energy becomes available and to promote the improvement of DG policy to protect the interests of all of the main bodies in the market after access to DG becomes available.

\subsubsection{A Benefit Impact Model for Grid Power Supply Enterprises after Access to Distributed Energy Becomes Available}

(1) A Forecast Model for Sales of Electricity considering the Features of Users' Demand for Distributed Energy. With the promotion and development of DG technology, a large number of industrial and residential users have begun to install and use DG. Compared with the traditional power market, in which the users are merely consumers of electricity, users equipped with DG are not only power consumers but also power producers with redundant DG power. Therefore, an analysis of the profit and loss relationship between distributed energy and grid power supply enterprises relies on a forecast of the sales of electricity according to the characteristics of the distributed users. The specific formulas are shown in (1)-(3).

The electricity which DG users purchase from the grid power supply enterprise is as follows:

$$
\mathrm{Q}=\mathrm{Q}_{d}-K \times M_{\mathrm{DG}}
$$
follows:

The annual power generation of distributed energy is as

$$
Q_{\mathrm{DG}}=M_{\mathrm{DG}} \times T \text {. }
$$

The electricity purchased by distributed energy users from a grid power supply enterprise is as follows:

$$
Q=Q_{d}-K \times M_{\mathrm{DG}} \times T,
$$

where $Q$ is the electricity which DG users purchase from a grid power supply enterprise, $Q_{d}$ represents the total electricity demand of the users, $K$ is the private use ratio of the distributed energy users, $Q_{\mathrm{DG}}$ is the annual power generation of distributed energy, $M_{\mathrm{DG}}$ is the capacity of distributed power, and $T$ is the annual use hour of distributed energy.

The users' total electricity consumption is closely related to the type of user, so forecasting the users' total electricity demand requires a combination of the types of users and a reasonable forecast based on the users' history of power consumption levels. The users can be divided into residential, industrial, and commercial users. The mode of access to the distributed energy system can be divided into "private use" and "a combination of private use and access to excess electricity" according to the different methods of power exchange; the user can choose the access mode. For the former type of user, all of the power generated through distributed energy is used by them, while, for the latter type of user, specific values can be predicted by historical data under normal circumstances. Under conditions in which the unit capacity of the distributed power supply is certain, the main factor influencing the generation of distributed power is the annual hours of use of distributed energy. The annual hour of use of distributed energy is related to the type of distributed energy; accordingly, the research should be classified.

(2) A Relationship Model for Access to Distributed Energy and the Benefits and Losses of Grid Power Supply Enterprises. Large-scale access to distributed PV will greatly affect the profits of grid power supply enterprises. Thus, grid power supply enterprises need to conduct some research and analysis to quantify the impact and formulate a good response.

In the traditional power market structure, without distributed PV, the trade relationship between the user and the grid power supply enterprise is shown as follows.

The power trade conditions before access to distributed energy are as follows:

\section{Power suppliers}

$$
\stackrel{P_{T}}{\longrightarrow} \text { Distribution Network } \underset{\mathrm{Q}_{0}}{\stackrel{P_{0}}{\longrightarrow}} \text { Power users. }
$$




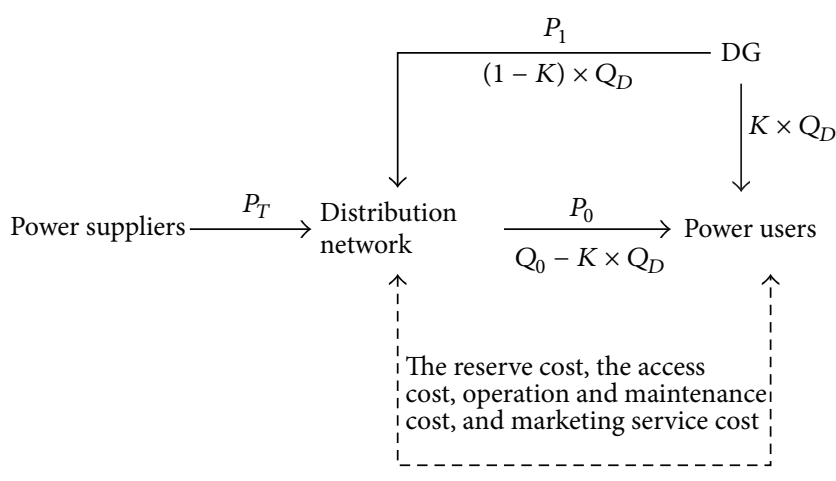

FIGURE 2: The relationship between the user and the grid power supply enterprise.

Among them, the profit of a grid power supply enterprise can be calculated using

$$
\begin{aligned}
I= & \left(1-t_{3}\right)\left\{\left[1-\frac{t_{1}}{1+t_{1}} \times\left(1+t_{2}\right)\right]\left(P_{0}-P_{T}\right)-C_{0}\right\} \\
& \times Q_{0},
\end{aligned}
$$

where $Q_{0}$ is the total power demand of electricity users; $P_{0}$ is the sales electricity price of these users which is stipulated by the government; $P_{T}$ is the feed-in tariff of power generation; $C_{0}$ is the unit distribution and business cost of grid power supply enterprise; $t_{1}$ is the value-added tax; $t_{2}$ is the additional expenses of education and the construction and maintenance of city; $t_{3}$ represents the income tax. After the access of distributed PV energy, the relationship between the user and grid power supply enterprise is shown in Figure 2.

It can be seen that this model not only considers changes in the sales of electricity, but also involves specific taxes, standby fees, service fees, and other aspects. The equations used to calculate the profits of grid power supply enterprises are shown:

$$
\begin{aligned}
A= & {\left[1-\frac{t_{1}}{1+t_{1}} \times\left(1+t_{2}\right)\right], } \\
R^{\prime}= & A \times P_{0} \times\left(Q_{0}-K \times Q_{D}\right)+\lambda_{1} \times M_{D}, \\
C^{\prime}= & A \times P_{T} \times\left(Q_{0}-Q_{D}\right)+P_{1} \times(1-K) \times Q_{D}+C_{0} \\
& \times\left(Q_{0}-K \times Q_{D}\right)+C_{J}+\lambda_{2} \times M_{D}, \\
I^{\prime}= & \left(1-t_{3}\right) \times\left(R^{\prime}-C^{\prime}\right),
\end{aligned}
$$

where $A=1-t_{1} /\left(1+t_{1}\right) \times\left(1+t_{2}\right)$ is the rate coefficient of value-added tax and the additional expenses of education and the construction and maintenance of city; $t_{1}$ is the value-added tax; $t_{2}$ is the additional expenses of education and the construction and maintenance of city; $R^{\prime}$ is the benefits of grid power supply enterprise after the access of distributed energy; $\lambda_{1}$ is the charging standard of standby fee according to the distributed energy unit capacity charged by grid power supply enterprise; $C^{\prime}$ is the cost of grid power supply enterprise after the access of distributed energy; $\lambda_{2}$ is

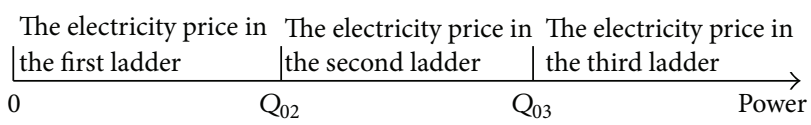

FIGURE 3: The principle of the ladder electricity price policy for the residential user.

the charging standard of standby fee charged by the power generation side; $C_{J}$ is the expense of the access cost, operation and maintenance cost, and market service cost after the access of distributed energy; $I^{\prime}$ is the profits of grid power supply enterprise after the access of distributed energy.

Combined with the profits of grid power supply enterprises before access to distributed energy, the reduction in the profits of grid power supply enterprises after access to distributed energy becomes available can be shown as follows:

$$
\begin{aligned}
\Delta I & =\left(1-t_{3}\right)\left\{\left[A \times\left(P_{0}-P_{T}\right)-C_{0}\right] \times K \times Q_{D}\right. \\
& +\left(P_{1}-A \times P_{T}\right) \times(1-K) \times Q_{D}+C_{J}+\left(\lambda_{2}-\lambda_{1}\right) \\
& \left.\times M_{D}\right\} .
\end{aligned}
$$

From a long-term perspective, access to distributed energy satisfies the demand of the users, so it may reduce line loss and the investment in transmission and distribution lines, which benefits grid power supply enterprises. This paper assumes these benefits as $\Delta S$, and the final reduction in the profits of grid power supply enterprises after access to distributed energy becomes available can be shown as follows:

$$
\begin{aligned}
\Delta I & =\left(1-t_{3}\right)\left\{\left[A \times\left(P_{0}-P_{T}\right)-C_{0}\right] \times K \times Q_{D}\right. \\
& +\left(P_{1}-A \times P_{T}\right) \times(1-K) \times Q_{D}+C_{J}+\left(\lambda_{2}-\lambda_{1}\right) \\
& \left.\times M_{D}\right\}-\Delta S .
\end{aligned}
$$

The formula above is just a general formula; in conditions involving different electricity price policies according to different kinds of users, the specific formulas of the final reduction in the profits will also change and will require specific analyses regarding different users, including residential, commercial, and industrial users and other kinds of users.

(a) The Residential Users. According to the current sales price policy in China, the ladder electricity price policy is applied to the residential user, and its specific principle is shown in Figure 3.

For residential users, the original power consumption level determines the degree of influence of distributed energy. The general formula above can be expressed in different forms, according to the different electricity consumption in three ladders.

If the electricity consumption of the residential users is in the first ladder before the installation of distributed energy, the impact on the profits of grid power supply enterprises 
after access to distributed energy by residential users can be expressed as follows:

$$
\begin{aligned}
\Delta I & =\left(1-t_{3}\right)\left\{\left[A \times\left(P_{01}-P_{T}\right)-C_{0}\right] \times K \times Q_{D}\right. \\
& +\left(P_{1}-A \times P_{T}\right) \times(1-K) \times Q_{D}+C_{J}+\left(\lambda_{2}-\lambda_{1}\right) \\
& \left.\times M_{D}\right\}-\Delta S,
\end{aligned}
$$

where $P_{01}$ is the sale electricity price of the residential users in the first ladder.

If the electricity consumption of the residential users is in the second ladder before the installation of distributed energy and the electricity consumption is still in the second ladder after the private use of distributed power, the impact on the profits of grid power supply enterprises after access to distributed energy by the residential users can be expressed as follows:

$$
\begin{aligned}
\Delta I & =\left(1-t_{3}\right)\left\{\left[A \times\left(P_{02}-P_{T}\right)-C_{0}\right] \times K \times Q_{D}\right. \\
& \left.+\left(\lambda_{2}-\lambda_{1}\right) \times M_{D}+C_{J}\right\}-\Delta S .
\end{aligned}
$$

In other conditions involving this price ladder, the impact on the profits of grid power supply enterprises after access to distributed energy by residential users can be expressed as follows:

$$
\begin{aligned}
\Delta I & =\left(1-t_{3}\right) \times\left\{\left[A \times\left(P_{02}-P_{T}\right)-C_{0}\right] \times\left(Q-Q_{02}\right)\right. \\
& \left.+\left[A \times\left(P_{01}-P_{T}\right)-C_{0}\right] \times\left(K \times Q_{D}-Q+Q_{02}\right)\right\} \\
& +\left(1-t_{3}\right)\left[\left(P_{1}-A \times P_{T}\right) \times(1-K) \times Q_{D}\right. \\
& \left.+\left(\lambda_{2}-\lambda_{1}\right) \times M_{D}+C_{J}\right]-\Delta S,
\end{aligned}
$$

where $P_{02}$ is the sale electricity price of the residential users in the second ladder; $Q_{02}$ is the threshold power of residential sale price between the first ladder and the second ladder; $Q$ is the actual electricity consumption of the residential users before the installation of distributed energy according to the condition that the electricity consumption of the residential users is in the second ladder; $\left(P_{02}-P_{T}\right) \times\left(Q-Q_{02}\right)$ is the profits impact on the grid power supply enterprise because of the electricity consumption loss in the second ladder after the use of distributed energy; $\left(P_{01}-P_{T}\right) \times\left(K \times Q_{D}-Q+Q_{02}\right)$ is the profits impact on the grid power supply enterprise because of the electricity consumption loss in the first ladder after the use of distributed energy.

If the electricity consumption of the residential users is in the third ladder before the installation of distributed energy, it is necessary to analyse the impact on profits on four conditions:

(1) If the private use of distributed power can satisfy the demand of residential users, the impact on the profits of grid power supply enterprises after access to distributed energy can be expressed as follows:

$$
\begin{aligned}
\Delta I & =\left(1-t_{3}\right) \times\left\{\left[A \times\left(P_{03}-P_{T}\right)-C_{0}\right] \times\left(Q-Q_{03}\right)\right. \\
& +\left[A \times\left(P_{02}-P_{T}\right)-C_{0}\right] \times\left(Q_{03}-Q_{02}\right)
\end{aligned}
$$

$$
\begin{aligned}
& +\left[A \times\left(P_{01}-P_{T}\right)-C_{0}\right] \times Q_{02}+\left(P_{1}-A \times P_{T}\right) \\
& \left.\times(1-K) \times Q_{D}+\left(\lambda_{2}-\lambda_{1}\right) \times M_{D}+C_{J}\right\}-\Delta S
\end{aligned}
$$

(2) If the residential users still need to purchase electricity after the private use of distributed energy and the purchased electricity is in the first ladder, the impact on the profits of grid power supply enterprises after access to distributed energy can be expressed as follows:

$$
\begin{aligned}
\Delta I & =\left(1-t_{3}\right) \times\left\{\left[A \times\left(P_{03}-P_{T}\right)-C_{0}\right] \times\left(Q-Q_{03}\right)\right. \\
& +\left[A \times\left(P_{02}-P_{T}\right)-C_{0}\right] \times\left(Q_{03}-Q_{02}\right) \\
& +\left[A \times\left(P_{01}-P_{T}\right)-C_{0}\right] \times\left(K \times Q_{D}-Q+Q_{02}\right) \\
& \left.+\left(\lambda_{2}-\lambda_{1}\right) \times M_{D}+C_{J}\right\}-\Delta S .
\end{aligned}
$$

(3) If the residential users still need to purchase electricity after the private use of distributed energy and the purchased electricity is in the second ladder, the impact on the profits of grid power supply enterprises after access to distributed energy can be expressed as follows:

$$
\begin{aligned}
\Delta I & =\left(1-t_{3}\right) \times\left\{\left[A \times\left(P_{03}-P_{T}\right)-C_{0}\right] \times\left(Q-Q_{03}\right)\right. \\
& +\left[A \times\left(P_{02}-P_{T}\right)-C_{0}\right] \times\left(K \times Q_{D}-Q+Q_{03}\right) \\
& \left.+\left(\lambda_{2}-\lambda_{1}\right) \times M_{D}+C_{J}\right\}-\Delta S .
\end{aligned}
$$

(4) If the residential users still need to purchase electricity after the private use of distributed energy and the purchased electricity is in the third ladder, the impact on the profits of grid power supply enterprises after access to distributed energy can be expressed as follows:

$$
\begin{aligned}
\Delta I & =\left(1-t_{3}\right) \times\left\{\left[A \times\left(P_{03}-P_{T}\right)-C_{0}\right] \times K \times Q_{D}\right. \\
& \left.+\left(\lambda_{2}-\lambda_{1}\right) \times M_{D}+C_{J}\right\}-\Delta S,
\end{aligned}
$$

where $P_{03}$ is the sale electricity price of the residential users in the third ladder; $Q_{03}$ is the threshold power of residential sale price between the second ladder and the third ladder; $Q$ is the actual electricity consumption of the residential users before the installation of distributed energy according to the condition that the electricity consumption of the residential users is in the third ladder.

(b) The Commercial Users. The impact of this kind of distributed energy users on the profits of grid power supply enterprises is simple, and the formula can be expressed as follows:

$$
\begin{aligned}
\Delta I & =\left(1-t_{3}\right)\left\{\left[A \times\left(P_{0}-P_{T}\right)-C_{0}\right] \times K \times Q_{D}\right. \\
& +\left(P_{1}-A \times P_{T}\right) \times(1-K) \times Q_{D}+\left(\lambda_{2}-\lambda_{1}\right) \\
& \left.\times M_{D}+C_{J}\right\}-\Delta S,
\end{aligned}
$$

where $P_{0}$ is the sales electricity price of commercial users. 
(c) The Industrial and Commercial Users That Are Related to Time-of-Use Electricity Prices or Two-Part Tariffs. The twopart tariff consists of a basic tariff and an electricity degree price, while the time-of-use electricity price consists of the electricity price at the peak time, the electricity price at a flat time, and the electricity price at a low time. Therefore, the impact on the profits of grid power supply enterprises of distributed industrial and commercial users with time-ofuse electricity prices or two-part tariffs can be expressed as follows:

$$
\begin{aligned}
\Delta I & =\left(1-t_{3}\right)\left\{\left[A \times\left(P_{F}-P_{T}\right)-C_{0}\right] \times Q_{\mathrm{DF}}\right. \\
& +\left[A \times\left(P_{P}-P_{T}\right)-C_{0}\right] \times Q_{\mathrm{DP}} \\
& +\left[A \times\left(P_{G}-P_{T}\right)-C_{0}\right] \times Q_{\mathrm{DG}}+\left(P_{1}-A \times P_{T}\right) \\
& \times\left[Q_{D}-\left(Q_{\mathrm{DF}}+Q_{\mathrm{DP}}+Q_{\mathrm{DG}}\right)\right]+\alpha\left(M_{0}-M_{0}^{\prime}\right)-\bar{\lambda} \\
& \left.\times M_{B}+C_{J}\right\}-\Delta S,
\end{aligned}
$$

where $P_{F}$ is the sales electricity price of industrial and commercial users in the peak time; $P_{P}$ is the sales electricity price of industrial and commercial users in the normal time; $P_{G}$ is the sales electricity price of industrial and commercial users in the off-peak time; $Q_{D F}, Q_{D P}$, and $Q_{D G}$ are the electricity consumption of private use in peak time, normal time, and off-peak time, respectively, after distributed energy installation of the industrial and commercial users; $\alpha$ is the basic price in the two-part tariff; $M_{0}$ is the capacity or maximum demand of the industrial and commercial users before the installation of distributed energy; $M_{0}^{\prime}$ is the capacity or maximum demand of the industrial and commercial users after the installation of distributed energy; $\bar{\lambda}$ is the reserve capacity expense; $M_{B}$ is the reserve capacity for the distributed energy users provided by the grid power supply enterprise; $Q_{\mathrm{DF}}+Q_{\mathrm{DP}}+Q_{\mathrm{DG}}$ is the annual private use of distributed power generation of distributed industrial and commercial users and its value is the same with $K \times Q_{D}$ in the formula above.

\section{Results}

For this study, the distributed PV of S province in China was selected as an example. The study examines the impact on the major players in the market after access to distributed power becomes available, especially the impact on the management of grid power supply enterprises.

3.1. The Basic Data. This paper studies the impacts on the management of grid power supply enterprises, combined with the specific situation of distributed energy and the related policy analysis of the development of distributed energy. This study uses the distributed PV of S province as an example to analyse the specific profits of grid power supply enterprises based on the model above. The related parameters of the model are shown in Tables 3 and 4 . Table 3 shows the basic parameters after access to distributed energy becomes available, and Table 4 shows the capacity situation for distributed energy.

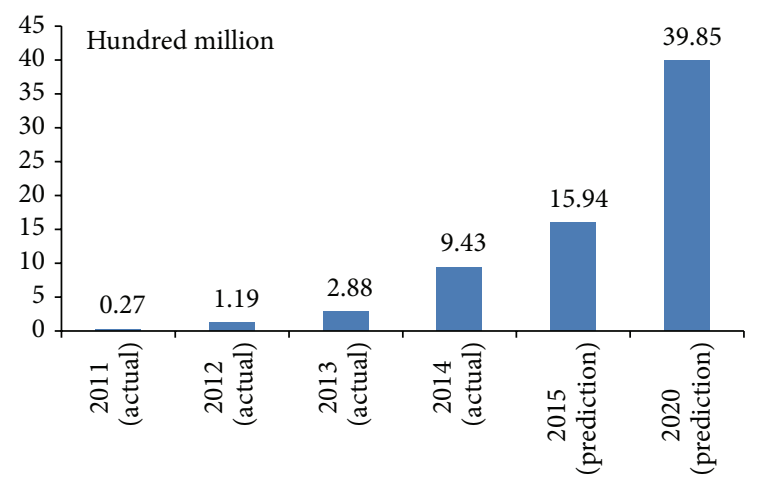

FIGURE 4: The beneficial impact on power supply enterprises in S province after access to distributed PV.

Among the distributed PV power users, residential users account for $20 \%$, business users account for $40 \%$, and industrial users account for $40 \%$. The private use ratio of industrial users between normal periods and peak periods is $2: 3$, as the off-peak time is usually in the evening, and the private use of industrial users with the installation of distributed PV power is 0 in the off-peak time. In the power consumption for private use of the distributed energy of residential users, the power consumption at the first electricity price level accounts for $60 \%$, and the power consumption at the second and third electricity price levels accounts for $30 \%$ and $10 \%$, respectively.

3.2. The Calculation of the Impact on the Benefits to Power Supply Enterprises after Access to Distributed Energy. Based on the basic data above and combined with the model, the beneficial impact on power supply enterprises after access to distributed energy can be calculated. The specific results are shown in Table 5.

Table 5 shows that access to distributed energy will gradually expand according to the current distributed energy development plan in China; accordingly, access to distributed energy will result in an increased beneficial impact for power supply enterprises in $\mathrm{S}$ province. The specific impact is shown in Figure 4.

Based on the results measured above, the beneficial impact on power supply enterprises in S province is not obvious, as the scale of current access to distributed PV is small, which causes a total loss of 0.943 billion yuan for the power supply enterprises in S province. However, an expanded scale of access to distributed PV will have a significant beneficial impact on the power supply enterprises in $S$ province. The economic loss of power supply enterprises in $\mathrm{S}$ province will reach 39.85 billion yuan in 2020, according to the current market model. However, the impact of access to excess electricity is 82.66 million yuan, and the impact of the private use is 280.33 million yuan. In general, with the continuous development of distributed energy, its impact on the total profits of power supply enterprises will become increasingly obvious in the future.

It is worth noting that this paper classifies the user in the calculation of the impact of private use on power supply enterprises and studies the impact of the private use of commercial, industrial, and residential users on the profits 
TABLE 3: The basic parameters after access to distributed energy becomes available.

\begin{tabular}{|c|c|c|c|}
\hline Item & Project & Unit & Value \\
\hline \multirow{3}{*}{$\begin{array}{l}\text { The cost } \\
\text { parameters }\end{array}$} & The feed-in tariff of distributed PV energy & Yuan/kWh & 0.431 \\
\hline & The access cost & Yuan/kW & 1500 \\
\hline & The operating cost & Yuan/kWh & 0.15 \\
\hline \multirow{3}{*}{$\begin{array}{l}\text { The equipment } \\
\text { parameters }\end{array}$} & The useful life of the distributed equipment & Year & 20 \\
\hline & The annual use hour & Hour & 1000 \\
\hline & The proportion of private use & $\%$ & $60 \%$ \\
\hline \multirow{13}{*}{$\begin{array}{l}\text { Tariff and tax } \\
\text { parameters }\end{array}$} & Residential electricity price (in the first ladder) & Yuan/kWh & 0.5283 \\
\hline & Power range of the first ladder & $\mathrm{kWh}$ & $0-160$ \\
\hline & Residential electricity price (in the second ladder) & Yuan/kWh & 0.5783 \\
\hline & Power range of the second ladder & $\mathrm{kWh}$ & $161-240$ \\
\hline & Residential electricity price (in the third ladder) & Yuan/kWh & 0.8283 \\
\hline & Power range of the third ladder & $\mathrm{kWh}$ & $241-\infty$ \\
\hline & Industrial electricity price (in peak time) & Yuan/kWh & 1.097 \\
\hline & Industrial electricity price (in flat time) & Yuan/kWh & 0.658 \\
\hline & Industrial electricity price (in low time) & Yuan/kWh & 0.319 \\
\hline & Commercial electricity price & Yuan/kWh & 0.867 \\
\hline & VAT $t_{1}$ & $\%$ & 17 \\
\hline & The additional expenses of education and the construction and maintenance of city $t_{2}$ & $\%$ & 10 \\
\hline & The income tax $t_{3}$ & $\%$ & 25 \\
\hline
\end{tabular}

TABLE 4: The capacity situation for distributed energy.

\begin{tabular}{lc}
\hline Year & The access capacity $(\mathrm{MW})$ \\
\hline 2011 (actual) & 20.4 \\
2012 (actual) & 89.6 \\
2013 (actual) & 216.7 \\
2014 (actual) & 710 \\
2015 (prediction) & 1200 \\
2020 (prediction) & 3000 \\
\hline
\end{tabular}

of power supply enterprises in S province after access to distributed energy becomes available. The specific results are shown in Table 6.

Table 6 shows that the impact of the private use of commercial, industrial, and residential users on the profits of power supply enterprises in S province is becoming increasingly obvious. Due to their access to excess electricity, the industrial and residential users create a loss of 36.86 and 32.08 million yuan to power supply enterprises in S province, respectively. The loss will increase annually and reach 155.75 and 135.54 million yuan in 2020 , respectively, according to current market conditions and electricity price structure and levels. At present, the residential users in this province use the ladder electricity price, and it will produce some losses for the power supply enterprises if the price of electricity is reduced from a high level to a low level. However, a cross-subsidy phenomenon exists in China for residential electricity price; namely, the sale price of residential electricity may be lower than its real power purchase cost. This may result in some benefits to power supply enterprises, and it can result in a

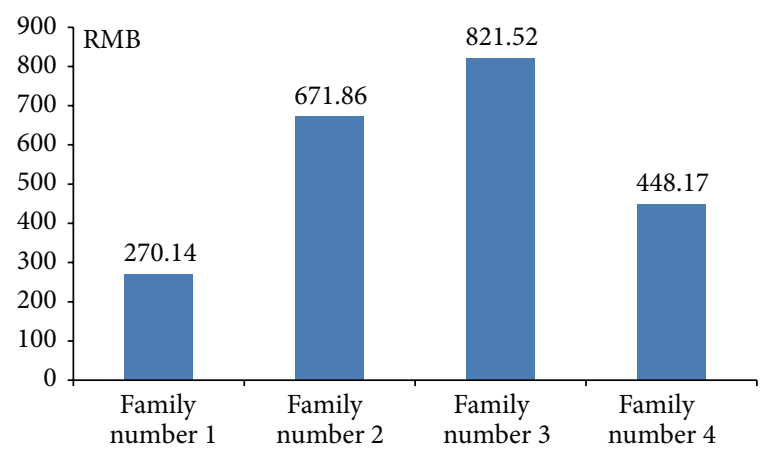

FIGURE 5: The beneficial impact on power supply enterprises caused by family number 1 to family number 4 .

benefit of 10.96 million yuan based on the current crosssubsidy level.

In order to see the ladder electricity price policy for residential user more clearly, this research take 4 families, for example. The access capacities in 4 families are all $5 \mathrm{~kW}$; the device will work for 2 hours every day; and the proportion of private use of the devices is $60 \%$. When there is no distributed energy, the electricity consumption of family number 1 to family number 4 is $2160 \mathrm{kWh}, 3600 \mathrm{kWh}, 4800 \mathrm{kWh}$, and $6000 \mathrm{kWh}$, respectively. Figure 5 will show the benefits impact on the grid power supply enterprise after the four families installed distributed energy at home under the ladder electricity price policy.

The private use of distributed energy in family number 1 is exactly the electricity consumption of this family; that is to say, the family is self-sufficiency after using distributed energy 
TABLE 5: The calculation of the beneficial impact on power supply enterprises in S province after access to distributed PV.

\begin{tabular}{|c|c|c|c|c|c|c|}
\hline Year & $\begin{array}{c}\text { The access } \\
\text { cost }\end{array}$ & $\begin{array}{c}\text { The cost of } \\
\text { operation and } \\
\text { maintenance } \\
\text { and marketing } \\
\text { service }\end{array}$ & $\begin{array}{c}\text { The benefits } \\
\text { impact of access } \\
\text { to excess } \\
\text { distributed } \\
\text { electricity }\end{array}$ & $\begin{array}{l}\text { The benefits } \\
\text { impact of the } \\
\text { private use }\end{array}$ & $\begin{array}{l}\text { The benefits impact } \\
\text { on the grid power } \\
\text { supply enterprise }\end{array}$ & $\begin{array}{l}\text { The benefits impact } \\
\text { on the grid power } \\
\text { supply enterprise } \\
\text { (after tax) }\end{array}$ \\
\hline 2011 (actual) & 0.306 & 0.031 & 0.0056 & 0.0191 & 0.36 & 0.27 \\
\hline 2012 (actual) & 1.344 & 0.134 & 0.0247 & 0.0837 & 1.59 & 1.19 \\
\hline 2013 (actual) & 3.251 & 0.325 & 0.0597 & 0.2025 & 3.84 & 2.88 \\
\hline 2014 (actual) & 10.65 & 1.065 & 0.1957 & 0.6634 & 12.57 & 9.43 \\
\hline 2015 (prediction) & 18 & 1.8 & 0.3307 & 1.1213 & 21.25 & 15.94 \\
\hline 2020 (prediction) & 45 & 4.5 & 0.8266 & 2.8033 & 53.13 & 39.85 \\
\hline
\end{tabular}

TABLE 6: The impact of the private use of different users on the profits of power supply enterprises in S province.

\begin{tabular}{|c|c|c|c|}
\hline Year & $\begin{array}{l}\text { The profit loss on } S \\
\text { province because of the } \\
\text { private use of commercial } \\
\text { users }\end{array}$ & $\begin{array}{l}\text { The profit loss on } S \\
\text { province because of the } \\
\text { private use of industrial } \\
\text { users }\end{array}$ & $\begin{array}{l}\text { The profit loss on } S \text { province } \\
\text { because of the private use of } \\
\text { residential users }\end{array}$ \\
\hline 2011 (actual) & 0.0106 & 0.0092 & -0.0007 \\
\hline 2012 (actual) & 0.0465 & 0.0405 & -0.0033 \\
\hline 2013 (actual) & 0.1125 & 0.0979 & -0.0079 \\
\hline 2014 (actual) & 0.3686 & 0.3208 & -0.0259 \\
\hline 2015 (prediction) & 0.6230 & 0.5422 & -0.0438 \\
\hline 2020 (prediction) & 1.5575 & 1.3554 & -0.1096 \\
\hline
\end{tabular}

devices. Due to this family, grid power supply enterprises' benefit will increase by 270.14 yuan. After the private use of distributed energy, family number 2 to family number 4 have changed from the third level users to the first, second, and third users. This will cause the benefit of grid power supply enterprises to increase by $671.86,821.52$, and 448.17 yuan, respectively. The profit increased by family number 4 is not apparently larger than family number 3; this is because the private use of distributed energy of family number 4 is very small compared to its own electricity consumption; that is, private electricity use is not enough to change the user's level of price.

This shows that the combination of the price ladder and distributed energy policy will not only help improve the social environment, but also help improve the economic efficiency of the grid. Additionally, from the user's perspective of view, this approach can reduce the user's electricity bill to a certain extent.

As a whole, the scale of access to distributed energy will have a large impact on the profits of grid power supply enterprises. That is to say, the impact of distributed energy on the profits of power supply enterprises will increase sharply under a policy environment which encourages the development of distributed energy. Accordingly, the government should establish a reasonable incentive policy system for the major players in the market to promote the sustainable development of distributed energy.

\section{Discussion}

From the perspective of promoting the exploitation of distributed energy and improving the efficiency of the utilisation of clean energy, the case above analyses the business impact on the major players in the power market after access to distributed energy becomes available. On this basis, we establish a model of the relationship of access to distributed energy and the benefits and losses of grid power supply enterprises in $S$ province and calculate the specific impact on the profits of it after access to distributed energy. Additionally, we choose 4 typical families to observe the impact on grid power supply enterprises when price ladder policy combines with distributed energy. Through this analysis and combined with the situation in China, the following can be seen:

(1) Access to distributed energy will directly affect the profits of grid power supply enterprises. The main factors are the increase in access costs, operation and maintenance costs, ancillary services, and marketing service costs, the reduction in power transmission and distribution income because of the private use of distributed energy, the difference in the feed-in tariff for distributed energy, and the reduction of the input tax deduction.

(2) The profits impact of the private use is different to commercial, industrial, and residential users. Commercial and industrial users will reduce the profit of grid power supply enterprises; and residential users will increase the 
profit of grid power supply enterprises a little bit. Currently, the scale of access to distributed energy is not large, and its impact on the profits of grid power supply enterprises is not obvious, just like family number 4 above. However, with the rapid development of distributed energy, its impact on grid power supply enterprises will become increasingly obvious.

(3) At present, China has not established a scientific and perfect compensation mechanism for distributed energy. Additionally, reasonable profits for the main market body cannot be guaranteed; accordingly, the government needs to establish a dynamic compensation mechanism to ensure reasonable profits for the main market body.

(4) Access to distributed energy increases operation and maintenance costs, the costs of ancillary services, and the costs of the marketing services of grid power supply enterprises. Based on a scientific analysis, the government should calculate the additional expenses of grid power supply enterprises after access to distributed energy becomes available, combined with the path of future reforms of the power market. Meanwhile, the relevant policies can be improved through linkage of the costs of electricity transmission and distribution in order to guarantee the support of grid power supply enterprises.

(5) Access to distributed energy will create some benefits to the major players in the market. Obviously, during the process of power market reforms in China, the government will require the implementation of a set of corresponding market mechanisms and modes of business operation to promote the healthy and orderly development of distributed energy.

(6) With the advancement of the reform process in the electric power market in China, the modes of management of grid power supply enterprises will be greatly changed. The relevant accounting standards and mechanisms for electricity prices will also be different. Thus, the beneficial impact model for grid power supply enterprises after access to distributed energy becomes available should be adjusted dynamically with the deepening of electricity market reforms.

\section{Conclusions and Policy Implications}

In order to realize the healthy and steady development of distributed energy, the government should improve the supporting policy system, develop market mechanisms and commercial operation modes which are helpful to the development of distributed energy, and promote all kinds of special policies to support the development of distributed energy. Through an analysis of the business impact of distributed energy on the major players in the market, this paper puts forward relevant policy recommendations regarding access to distributed energy. The specific conclusions and policy implications are shown as follows:

(1) In terms of access costs, in accordance with the existing policies and regulations, the access costs of distributed energy are mainly borne by grid power supply enterprises, while DG users only bear a small part of it. Accordingly, the relevant cost of grid power supply enterprises will increase to some degree and the enthusiasm of grid power supply enterprises will decrease, which may not be conducive to the healthy and sustainable development of distributed energy. A mechanism where the access costs can be shared by all players in the market should be established by the government, DG users, and grid power supply enterprises in the future.

(2) In terms of ancillary services, grid power supply enterprises provide all kinds of ancillary services for DG users, and the power plant bears these costs, so a sharing mechanism cannot guarantee a reasonable income for power generation enterprises. In conclusion, a compensation mechanism should be established requiring DG users to bear the cost of ancillary services.

(3) In terms of a compensation mechanism for the users, the current compensation mechanism has serious problems and subsidies have not been put in place in a timely manner. This is not conducive to the development of distributed energy. In order to ensure the enthusiasm of distributed energy users and to guarantee the healthy and orderly development of distributed energy, reasonable profits for distributed energy users should be guaranteed during the early stages of access to distributed energy. Thus, the degree of electricity subsidy can be used to ensure reasonable profits for distributed energy users and a dynamic adjustment in the subsidy mechanisms should be made to promote the technology and management of distributed energy.

(4) In terms of market mechanisms and business models, in order to balance the interests of the major players in the market after access to distributed energy and to promote the further development of distributed energy, social management, taxation, and market-oriented reforms should be taken into consideration when the government develops relevant policies. Meanwhile, some measures can be taken to promote the development of distributed energy, including a carbon tax and a resource tax, a reflection of the real costs of power supply, and a reduction in the cost of generating distributed power.

(5) Electricity market reforms in China should promote accounting mechanisms for electricity distribution in power grid enterprises and the marketization of electricity prices, so as to reduce the effects of access to distributed electricity. Simultaneously, set up sound electricity price mechanisms on the profits of grid power companies.

\section{Competing Interests}

The authors declare that they have no competing interests.

\section{Acknowledgments}

The work described in this paper was supported by the National Natural Science Foundation of China (Grant no. 71273089) and the National Social Science Major Projects Fund (Grant no. 15ZDB165).

\section{References}

[1] P. M. Murphy, S. Twaha, and I. S. Murphy, "Analysis of the cost of reliable electricity: a new method for analyzing grid connected solar, diesel and hybrid distributed electricity systems considering an unreliable electric grid, with examples in Uganda," Energy, vol. 66, pp. 523-534, 2014. 
[2] W. El-Khattam and M. M. A. Salama, "Distributed generation technologies, definitions and benefits," Electric Power Systems Research, vol. 71, no. 2, pp. 119-128, 2004.

[3] L. Tshewang, "Rural electrification in Bhutan and a methodology for evaluation of distributed generation system as an alternative option for rural electrification," Energy for Sustainable Development, vol. 12, no. 3, pp. 13-24, 2008.

[4] G. Pepermans, J. Driesen, D. Haeseldonckx, R. Belmans, and W. D'haeseleer, "Distributed generation: definition, benefits and issues," Energy Policy, vol. 33, no. 6, pp. 787-798, 2005.

[5] C. Murphy, A. Soroudi, and A. Keane, "Information gap decision theory-based congestion and voltage management in the presence of uncertain wind power," IEEE Transactions on Sustainable Energy, vol. 99, pp. 1-9, 2015.

[6] A. Soroudi, "Possibilistic-scenario model for DG impact assessment on distribution networks in an uncertain environment," IEEE Transactions on Power Systems, vol. 27, no. 3, pp. 12831293, 2012.

[7] M. Jaccard and M. Yushi, "A framework for social costing and institutional/market reform in the Chinese energy sector," Energy for Sustainable Development, vol. 5, no. 4, pp. 100-110, 2001.

[8] A. A. Bayod-Rújula, "Future development of the electricity systems with distributed generation," Energy, vol. 34, no. 3, pp.377383, 2009.

[9] A. Soroudi, M. Ehsan, and H. Zareipour, "A practical ecoenvironmental distribution network planning model including fuel cells and non-renewable distributed energy resources," Renewable Energy, vol. 36, no. 1, pp. 179-188, 2011.

[10] M. L. Holtmeyer, S. Wang, and R. L. Axelbaum, "Considerations for decision-making on distributed power generation in rural areas," Energy Policy, vol. 63, no. 12, pp. 708-715, 2013.

[11] S. Martin and J. Susanto, "Supplying power to remote villages in Lao PDR.-The role of off-grid decentralised energy options," Energy for Sustainable Development, vol. 19, no. 1, pp. 111-121, 2014.

[12] W. N. Macêdo and R. Zilles, "Influence of the power contribution of a grid-connected photovoltaic system and its operational particularities," Energy for Sustainable Development, vol. 13, no. 3, pp. 202-211, 2009.

[13] M. Zeng, K. Tian, C. Li, and N. Li, "Method of capacity compensation for independent distributed generation in distribution network within the context of smart grid," in Proceedings of the IEEE Power and Energy Engineering Conference (APPEEC '10), pp. 1-5, Chengdu, China, March 2010.

[14] J. Liu, R. Wang, Y. W. Sun, Y. J. Lin, and L. S. Xiao, "A barrier analysis for the development of distributed energy in China: a case study in Fujian province," Energy Policy, vol. 60, no. 9, pp. 262-271, 2013.

[15] F. Zhang, H. Deng, R. Margolis, and J. Su, "Analysis of distributed-generation photovoltaic deployment, installation time and cost, market barriers, and policies in China," Energy Policy, vol. 81, pp. 43-55, 2015.

[16] B. Dupont, C. D. Jonghe, L. Olmos, and R. Belmans, "Demand response with locational dynamic pricing to support the integration of renewables," Energy Policy, vol. 67, no. 4, pp. 344-354, 2014.

[17] D. Azofra, E. Jiménez, E. Martínez, J. Blanco, and J. C. SaenzDíez, "Economical-environmental impact of subsidised renewable energy sources for electricity (RES-E) in the Spanish system," Energy for Sustainable Development, vol. 29, pp. 47-56, 2015.
[18] G. W. Hong, N. Abe, M. Baclay Jr., and L. Arciaga, "Assessing users' performance to sustain off-grid renewable energy systems: the capacity and willingness approach," Energy for Sustainable Development, vol. 28, pp. 102-114, 2015.

[19] P. Lv and F. Spigarelli, “The integration of Chinese and European renewable energy markets: the role of Chinese foreign direct investments," Energy Policy, vol. 81, no. 6, pp. 14-26, 2015.

[20] R. Cossent, T. Gómez, and P. Frías, “Towards a future with large penetration of distributed generation: is the current regulation of electricity distribution ready? Regulatory recommendations under a European perspective," Energy Policy, vol. 37, no. 3, pp. 1145-1155, 2009. 


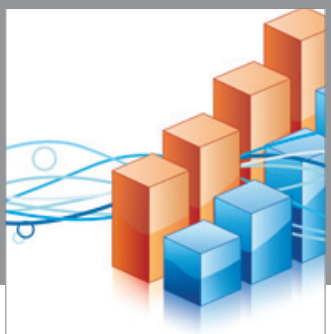

Advances in

Operations Research

vatem alat4

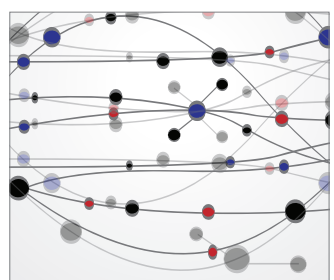

\section{The Scientific} World Journal
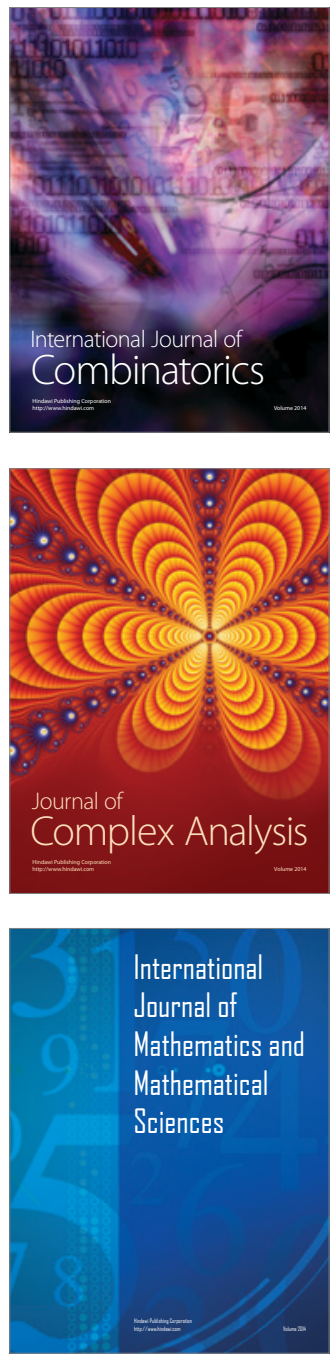
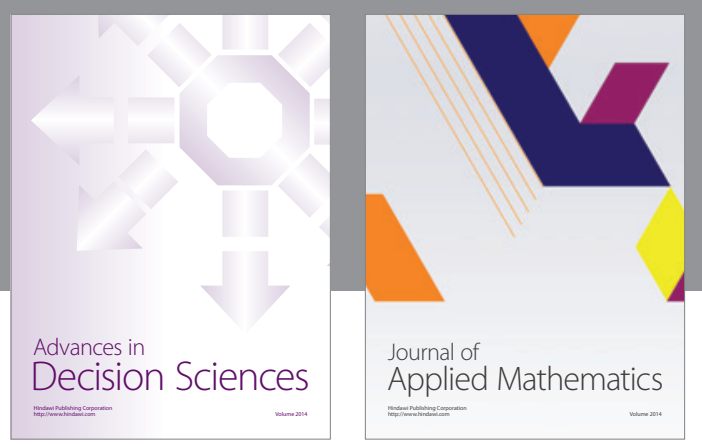

Algebra

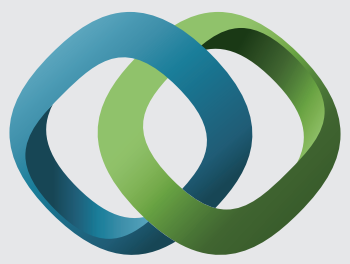

\section{Hindawi}

Submit your manuscripts at

http://www.hindawi.com
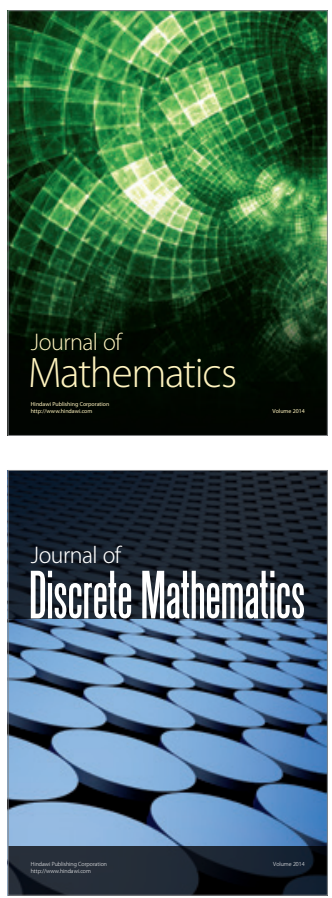

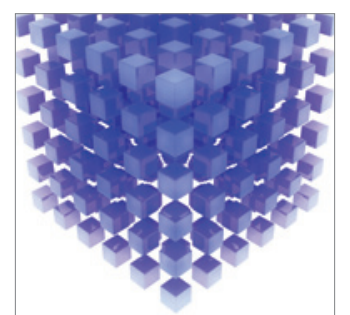

Mathematical Problems in Engineering
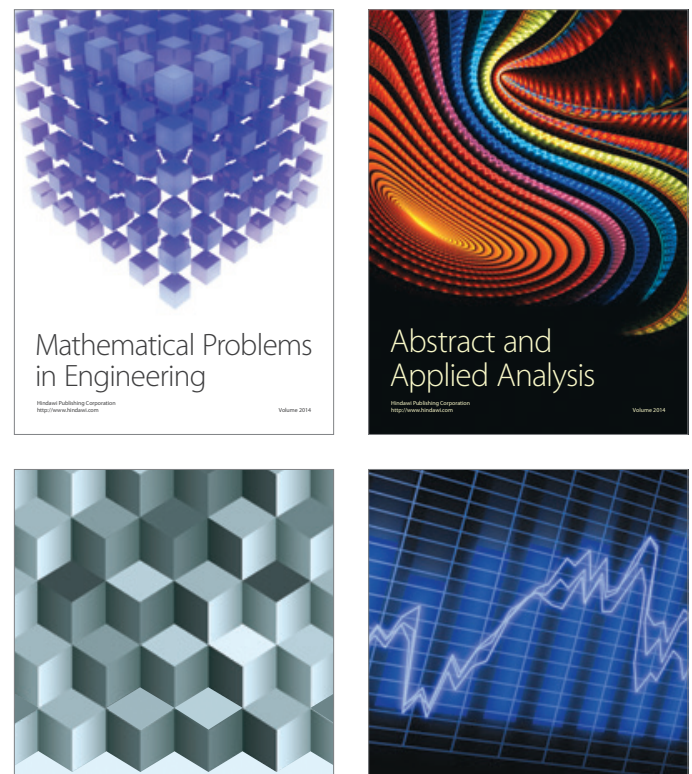

Journal of

Function Spaces

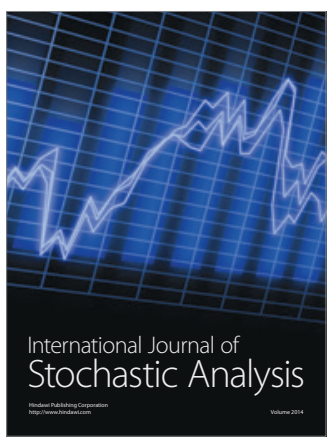

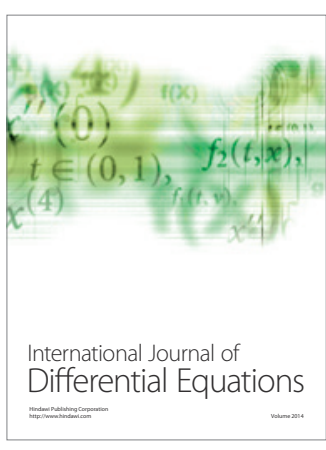
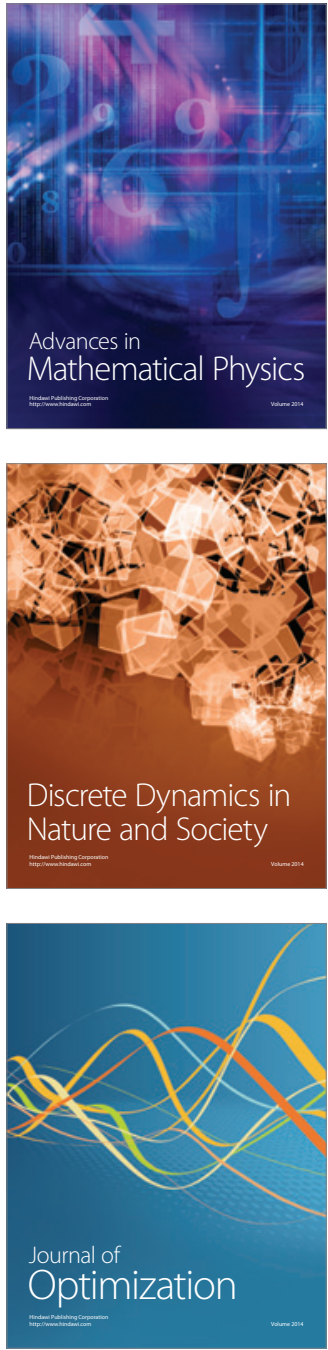